Portland State University

PDXScholar

Spring 2021

\title{
A Comparison of Particulate Matter Deposition onto Green Roof Species and White Roof in Portland, Oregon
}

Amelia Drake

Portland State University

Follow this and additional works at: https://pdxscholar.library.pdx.edu/honorstheses

Part of the Environmental Engineering Commons

Let us know how access to this document benefits you.

\section{Recommended Citation}

Drake, Amelia, "A Comparison of Particulate Matter Deposition onto Green Roof Species and White Roof in Portland, Oregon" (2021). University Honors Theses. Paper 1117.

https://doi.org/10.15760/honors.1145

This Thesis is brought to you for free and open access. It has been accepted for inclusion in University Honors Theses by an authorized administrator of PDXScholar. Please contact us if we can make this document more accessible: pdxscholar@pdx.edu. 


\title{
A Comparison of Particulate Matter Deposition onto Green Roof Species and White Roof in Portland, Oregon
}

\author{
by
}

Amelia Drake

An undergraduate honors thesis submitted in partial fulfillment of the

\author{
requirements for the degree of \\ Bachelor of Science \\ in \\ University Honors \\ and \\ Environmental Engineering
}

Thesis Adviser

Olyssa Starry, PhD

Portland State University

Spring 2021 


\section{Acknowledgements}

This project would not have been possible without the help of Alondra Sotelo Laureano and Tyler Robin, who spent hours helping me with the process of measuring leaf area. And of course, Olyssa Starry who helped with sample collection, experimentation, and analysis - while motivating and guiding me throughout this entire process. Additionally, funding from the National Institutes of Health Common Fund and Office of Scientific Workforce Diversity under the following awards: UL1GM118964, RL5GM118963, and TL4GM118965 supported this project throughout the entire research process. 


\section{Table of Contents}

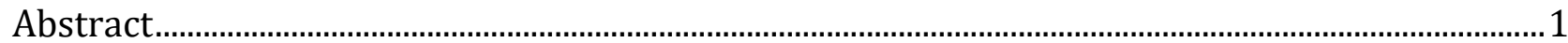

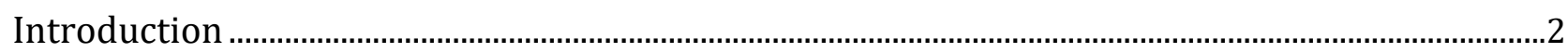

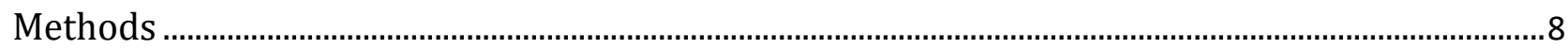

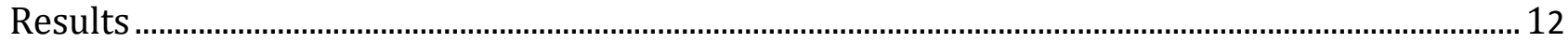

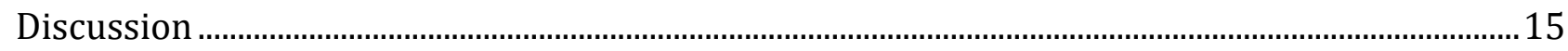

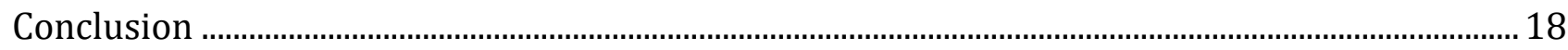

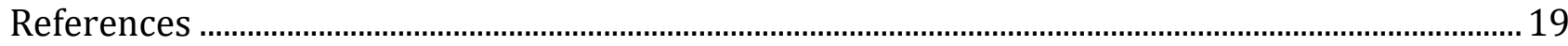

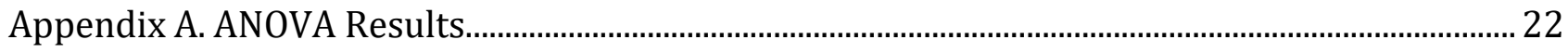




\begin{abstract}
With an increasing percentage of the world's population living in urban areas, we are likewise seeing increasing levels of toxic pollutants found in urban areas. This study explores the following question: how do different green roof vegetation species contribute to particulate matter deposition relative to a white roof in Portland, Oregon? To answer this question, replicate samples of rinse water particulates from two succulent species of vegetation - S. kamchaticum and S. rupestre - were compared to rinse water from white roof surfaces. Leaf area was then determined in order to calculate the density of particles found oneach surface. White roof samples were normalized to the known roof surface and plants samples were normalized to leaf area. Values for particle densities were initially similar across the surfaces - with the density of $10 \mu \mathrm{m}$ diameter particles found on S. kamchaticum and white roof both in the magnitude of $10^{-5} \mathrm{~g} / \mathrm{cm}^{2}$. However, when taking into account leaf area index, a larger density of particles was found to be collected on vegetative surfaces as opposed to the surface of the white roof. The density of specific metals present on each surface was also determined and compared. Although S. kamchaticum contained a higher density of particles, the white roof may be more effective at collecting particular metals such as iron and aluminum. It would be beneficial for future research to consider why particular metal species are more found at higher densities on specific surfaces.
\end{abstract}




\section{Introduction}

An increased awareness of ambient air quality has been accompanied by increasing levels of harmful pollutants in the atmosphere, as a result of rapid urbanization and industrialization (Suravarapu, 2016). The Global Burden of Disease Study conducted in 2017 shows that environmental factors strongly contribute to the likelihood of disability caused by chronic obstructive pulmonary disease - especially within countries whose sociodemographic index is low (Soriano et al, 2017). Instances of chronic pulmonary disease associated with particulate matter emissions account for 250 global deaths per 100,000 people per day (Soriano et al, 2017). In the western US, recent wildfires as a result of climate change have resulted in ambient particulate matter concentrations as high as 490 $\mu \mathrm{g} / \mathrm{m}^{3}$ - 14 times that of the Environmental Protection Agency's air quality guidelines for 24-hour exposure (EPA NAAQS). Particulate matter is often organized into three categories based on particle size: $\mathrm{PM}_{10}$ (coarse particles, diameter is $\leq 10 \mu \mathrm{m}$ ), $\mathrm{PM}_{2.5}$ (fine particles, diameter is $\leq 2.5 \mu \mathrm{m}$ ), and $\mathrm{PM}_{0.1}$ (ultra-fine particles, diameter is $\leq 0.1 \mu \mathrm{m}$ ). Particles that are smaller often pose a greater health risk because they're able to travel deeper into one's lungs, and $\mathrm{PM}_{0.1}$ is even small enough to enter the bloodstream (Weerakkody, 2017).

Depending on the composition of the particulate matter, this risk can be carcinogenic or fatal. Heavy metals can enter the body through inhalation from the ambient air and through ingestion - or from particulate matter that has deposited onto the produce that we harvest (Suravarapu, 2016). Although the human body can tolerate - and oftentimes requires - small amounts of particular metals, larger levels of toxic pollutants, such as Chromium IV or lead, can be lethal (Artwell, 2017). Environmental levels are increasing this can be seen by the increase in the concentration of these pollutants that deposit onto the surface of vegetation (Tomašević et al, 2005). Traffic emissions are regarded as being 
one of the greatest promoters for these increased levels; it is widely understood that exposure to traffic emissions increases the risk of healtheffects for those living or working near roadways (Baldauf, 2017). In fact, in several epidemiological studies, there were less accounts of doctors' visits during periods of decreased traffic levels (Bell et al, 2011). Exposure to traffic-related emissions are greatest in urban areas - wherein $68 \%$ of the population is projected to live by 2050 (UN DESA, 2018). Researchers found increasing levels of heavy metals on tree leaves in Belgrade as the population of the city increased (Tomašević et al, 2005) and shocking combinations of metals found in pine needles near a petrochemical plant - both suggesting that our growing proximity to industrial activities may heed some negative consequences (Bosco et al, 2005).

Despite the growing concerns regarding the health of city-dwellers and cities, many studies have shown that air pollution is not necessarily an irremediable issue. Air quality measurements taken along the height of a 60-story building in downtown Chicago found that both $\mathrm{PM}_{1}$ and $\mathrm{PM}_{2.5}$ concentrations tended to decrease with building height (Stephens et al, 2019). Urban street canyons occur when tall buildings adjacent to a street result in a lack of air dispersion, therefore causing a "canyon" of poorer air quality. However, it has been shown that $\mathrm{NO}_{2}$ and $\mathrm{PM}_{10}$ concentrations can be reduced by as much as $40 \%$ and $60 \%$ respectively, by the addition of vegetation to these microenvironments (Pugh et al, 2012). Vegetation as a form of air pollution remediation is not a new idea - a study conducted in 1997 showed that although it can have toxic effects on the trees, urban woodlands are effective at capturing particulate matter due to the large surface area contained therein (Beckett et al, 1998). Later on, additional research suggested that different species of shrubs also function as bioremediators - and are potentially more effective than trees (Chen et al, 2016). Other studies have looked at roadside barriers as effective forms of vegetative 
remediation (Tong et al, 2016 and Brantley et al, 2014). In their study done on the effectiveness of roadside barriers to reduce air pollution, Tong et al found that although solid-barriers provide a large concentration drop across the barrier, a vegetation-solid combination barrier provides a higher reduction in downwind PM concentrations (Tong et al, 2016).

To utilize green infrastructure as a remediation method for air pollution, we must also take into account evidence that suggests differences in particulate matter deposition depending on surface characteristics - such as leaf micromorphology. Similarly to how different plant families - like shrub-like plants versus trees - may be more effective, different species may also have different levels of effectiveness in retaining particles (Chenet al, 2016). For example, it was found that "the dust-retaining capability of any given tree species is significantly different in the same [geographical] place" (Liu et al, 2012). Many studies have illustrated that particular micromorphological characteristics, like "vegetation with rough surfaces \& fine hairs or raised veins", are often more effective at capturing and retaining particles (Moya et al, 2018). A study using synthetic leaves as a way of exploring these characteristics found that smaller leaves tend to be more efficient at capturing particles, which they suggested was due to the large edge effect of smaller leaves (Weerakkody et al, 2018). These micromorphological characteristics can vary widely and because they often impact the efficacy of green infrastructure, they are considered to be one of the most important design factors in considering vegetation as a bioremediator (Saebo et al, 2012). 
Several studies have questioned the notion that vegetation can serve as a bioremediator of urban particulate matter pollution. In evaluating the efficacy of vegetative roadside barriers in traffic pollution mitigation, researchers saw a "modest improvement in near-road concentrations of PM" in some cases. However, they also saw an increase in PM concentrations in other cases - due to the recirculation zones created by the boundary edge effects of the barrier (Brantley et al, 2014). These unintended consequences of vegetative barriers bring attention to the fact that not all green infrastructure is created equal. There is also emerging evidence to suggest that "trees do not necessarily improve air quality in near-road environments", due to the fact that dense vegetation near roads may result in reduced ventilation and therefore worsen air quality (Viippola et al, 2020). From the lack of consensus in the literature, one must agree with Janhall et al, that "we do not yet understand all the parameters influencing the effects of vegetation on air pollution" (Janhall et al, 2015).

More work is needed to understand how low impact designs, such as green roofs, can affect urban air quality. Green roofs have gained popularity in recent years as an effective form of bioremediation infrastructure and a possible solution to a myriad of environmental issues. Temperature regulation has been promoted as a promising benefit of green roofs. Green roofs are able to facilitate cooling by offering shade, by absorbing thermal energy through the process of photosynthesis and by the process of evapotranspiration; in fact "green roofs reflect between $20 \%$ and $30 \%$ of solar radiation, and absorb up to $60 \%$ of it through photosynthesis" (Berardi et al, 2014). Compared to other forms of vegetative infrastructure, one of the obvious advantages of green roofs is that they can be built onto a pre-existing landscape, while planting street trees - for example - often requires a disruption of the urban environment (Speak et al, 2012). As is 
generally true about vegetation as a bioremediation solution, the characteristics of green roofs and green roof vegetation impact the efficacy of these projects as well. One of the few studies that looks at PM deposition onto green roofs argues that while green roofs are "an effective option to mitigate air pollution as well as other environmental problems", they should not be the only method (Yang et al. 2008). It was estimated that approximately $2.3 \%$ of inputted $\mathrm{PM}_{10}$ in the area surrounding green roofs was captured by a collection of green roofs studied in a UK city - making them "less effective than street trees" (Speak et al, 2012). However, it appears that choice of species will affect this efficacy - for example, the high leaf roughness of Sedum album makes it much more effective when compared to other common green roof species (Viecco et al, 2018). Furthermore, proximity to the source of pollution also has an effect on deposition rates seen in vegetation in general where deposition rates are greater on vegetation that is closer to sources of pollution (Janhall et al, 2015). This is another trend that likely impacts green roof vegetation and should be accounted for.

In judging the efficacy of green roofs as a form of environmental bioremediation, one must consider the other logical option - white roofs. White roofs - also known as cool roofs essentially increase the albedo of a roof, thereby reducing temperatures of the building and potentially the surrounding environment. Albedo is a unitless quantity that represents the reflectiveness of a surface. On average, white roofs are able to achieve a near-surface air temperature reduction of 0.2 Kelvin per 0.1 increase in roof albedo (Wang et al, 2020). Previous research has indicated that pollutant uptake is much greater by vegetative walls compared to hard surfaces like concrete facades (Joshi \& Ghosh, 2014), however there is a need for a direct comparison of white roofs to ecoroof vegetation - which is the goal of the study at hand. Furthermore, it has been determined that a non-green roof would need to have an albedo of at least 0.7 in order to achieve the same reduction in surface temperature 
as a green roof (Li et al, 2014). This implies that if white roofs are in fact collecting and retaining particulate matter, this may actually result in a loss of efficacy to reflect solar radiation and act as a thermal regulator.

The question being asked in this study is how do different green roof vegetation species contribute to particulate matter deposition relative to a white roof in Portland, Oregon? Previous research indicates that we will find a variation in the particle concentrations among green roof species. We will also look at differences between particulate matter concentration of leaf surface with the PM concentration of the surface of a white roof at the same location - we believe we will find a higher concentration of PM on the sampled vegetative surfaces. Additionally, this study will look at the specific composition of metals captured on each respective surface. Using inductively coupled plasma mass spectrometry to determine the masses of particular metals present, we want to determine 1) if vegetation is more effective than white roofs at collecting particles, but more importantly 2) variations in the composition of the particles collected on vegetation versus white roofs because as previously illustrated, not all particles have the same effects on human health. 


\section{Methods}

Site Characteristics

The roof sampled in this study was located on a Walmart in NE Portland, Oregon. The same roof was used to sample both ecoroof vegetation and white roof. We intentionally chose to sample in late fall, after a long dry summer, in order to capture maximum loading conditions.

\section{Sampling}

We sampled two different species of plants from this ecoroof in order to encompass any variations in PM concentration caused by variation in micromorphological characteristics. For both plant species there were four replicates. The species sampled were Sedum kamchaticum and Sedum rupestre. For both the leaves and white roof, composite samples were taken along four evenly spaced transect lines. For the plants, multiple samples were taken from ten plus locations - because many plants were entering winter dormancy. To obtain a sample from the white roof, we placed a rim on the surface of the white roof, added a known volume of water, agitated the water and then retrieved the water sample using a baster. For the white roof, four composite samples were taken $20 \mathrm{ft}$ apart along the transect. Sampling two different species of vegetation was valuable because it has allowed us to look at the variation among species compared to the observable differences between white roofs and vegetation.

\section{Measurement of Particulate Matter}

The gravimetric method employed by Dzierżanowski et al was used to obtain values for the mass of deposited particulate matter on the vegetation samples. The mass of particulate matter per leaf was determined gravimetrically using a Buchner funnel, filter and vacuum pump system (Figure 1), and then the particulate matter density was 
calculated by normalizing the mass values by the surface area of the leaves. Previous studies have already shown that this method is successful in obtaining a reasonable estimation for the amount of deposited particulate matter for other forms of urban vegetation such as urban forests (Dzierżanowski et al, 2011). This method involved agitating the sampled leaves in rinse water in order to suspend the particles within the water so they can then be filtered, captured and weighed. We decided to sample for only the surface particulate matter - sampling the PM concentration of the in-wax layer would require rinsing in chloroform rather than water - because it has been shown that the in-wax PM concentration is often negligible compared to the surface concentration (Chen et al, 2017). To measure the particulate matter concentration of the white roof "sample", we agitated water within a known roof surface area and then processed that rinse water the same way as the leaf rinse water.

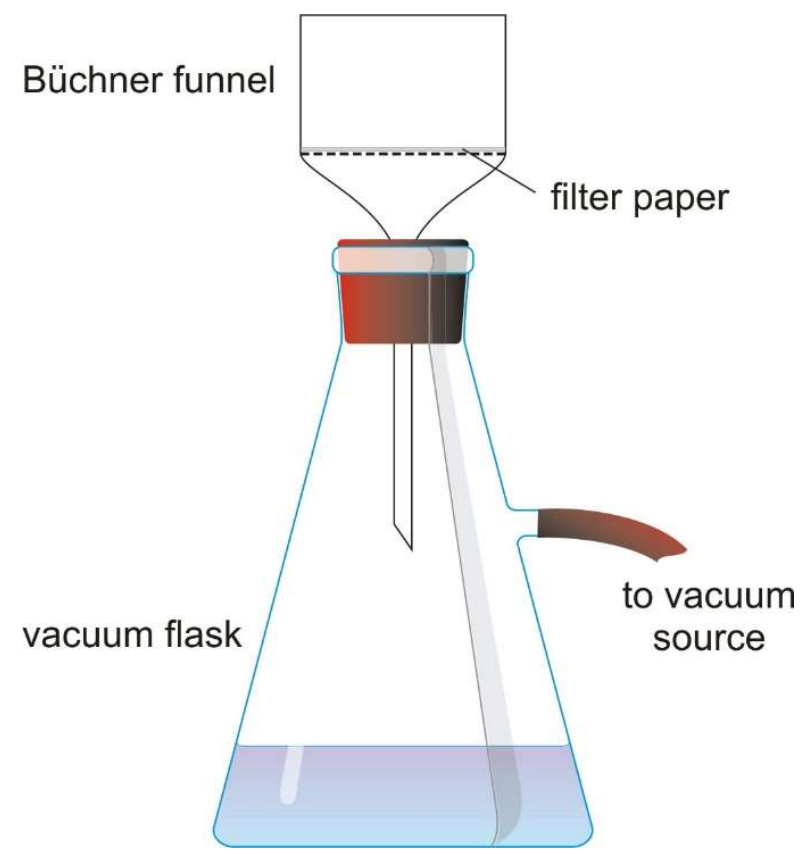

Figure 1. Buchner funnel and vacuum pump used to filter rinse water. 
Surface Area Measurement

In addition to collecting leaf rinse water, we measured the surface area of the leaves so we could obtain a mass per unit area measurement for particulate matter concentration. For the flat leaf species we sampled - Sedum kamchaticum - we measured leaf area using an LI-3100 area machine and then we tested the accuracy of the machine using an additional method, namely a pixel counting process shown in several other studies (Chen et al, 2016 and Chen et al, 2017). This process consisted of us laying each leaf out flat, taking a photo, and then using a combination of Adobe Photoshop and ImageJ to obtain a pixel-count (Figure 2).

For the smaller, more rounded leaf species - Sedum rupestre - we used the relationship between volume and surface area of a cylinder in order to determine the surface area per leaf (Starry, 2013). Surface area of the white roof was a known value, determined by the surface area of the rim used to obtain the sample.
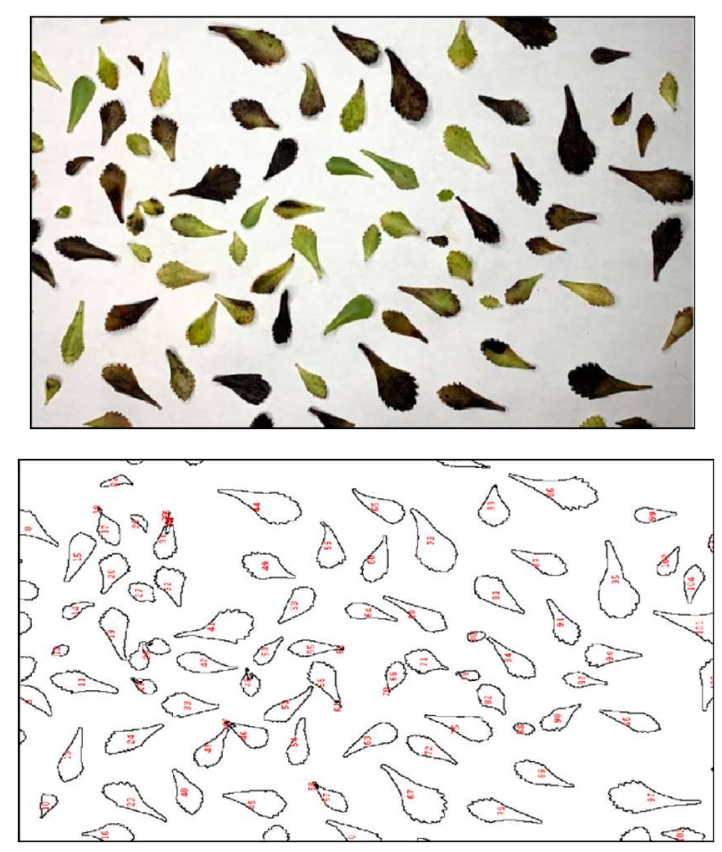

Figure 2. Sedum kamchaticum leaves photographed, edited in Adobe Photoshop - we then used ImageJ to determine the total leaf area present in each image 
Analysis of Metals

After a mass measurement was obtained, the filters were sent to Pennsylvania State University, where they offered to digest our filters and conduct a metals analysis using inductively coupled plasma mass spectrometry (ICP-MS).

\section{Data Processing}

To account for the layering effect of vegetation, we needed to consider the Leaf Area Index (LAI) of the vegetation species sampled. When we measured the total area of the leaves in the sample, we assumed that the leaves were lying flat on a surface; but this does not accurately represent the natural position of the leaves on the ecoroof. To accurately represent the density of particulate matter on the leaf surfaces, we multiplied the calculated density values by the LAI for each species. Both the corrected and uncorrected values are included in the Results section of this study. Leaf Area Index is a constant that varies from species to species - for Sedum kamchaticum and Sedum rupestre the LAI values are 5.93 and 10.45 , respectively. These values were determined in a previous study looking at ecoroof vegetation (Starry, 2013) - these constants represent the amount of layering that is occurring in the plant's growing pattern.

The ICP-MS analysis was conducted by Pennsylvania State University and the mass

values were provided in units of milligrams of metals per sample. In order to meaningfully compare these values for the three different surfaces, we took the concentration in $\mathrm{mg} / \mathrm{sample}$ and divided it by the area of the sample - to obtain a value of the density of metal particles in each sample.

\section{Statistical Data Analysis}

An analysis of variance (ANOVA) test and a Tukey's post-hoc Honestly Significant Difference test (Tukey's HSD) were conducted in order to determine if the differences seen 
in the results were significantly different. The result of this statistical analysis can likewise be found in the Results section of this paper.

\section{Results}

This study produced two different types of data. From the rinsing and filtering of the leaves, surface particles were collected. The mass of these particles was measured using a Buchner funnel, as described above. This value was then normalized to the total area of the samples, to obtain a density value (Table 1 ).

Table 1. Raw data showing surface area of each sample, particle mass present, and the density of particles found.

\begin{tabular}{|c|c|c|c|c|c|c|}
\hline \multicolumn{7}{|c|}{0.2 micrometer filter } \\
\hline sample & $\begin{array}{l}\text { area sum } \\
\left(\mathrm{cm}^{2}\right)\end{array}$ & $\begin{array}{l}\text { dry pre-filter } \\
\text { mass (g) }\end{array}$ & $\begin{array}{l}\text { dry post-filter } \\
\text { mass (g) }\end{array}$ & $\begin{array}{c}\text { mass of } \\
\text { particles (g) }\end{array}$ & $\begin{array}{c}\text { PM density } \\
\left(\mathrm{g} / \mathrm{cm}^{2}\right)\end{array}$ & $\begin{array}{c}\text { PM density - } \\
\text { corrected } \\
\left(\mathrm{g} / \mathrm{cm}^{2}\right)\end{array}$ \\
\hline $\operatorname{kam} 1$ & 384.06446 & 0.34429 & 0.34991 & $6.74 \mathrm{E}-03$ & $1.76 \mathrm{E}-05$ & $1.04 \mathrm{E}-04$ \\
\hline $\operatorname{kam} 2$ & 316.059 & 0.33787 & 0.34155 & $4.26 \mathrm{E}-03$ & $1.35 \mathrm{E}-05$ & $7.99 \mathrm{E}-05$ \\
\hline kam3 & 211.672 & 0.33758 & 0.34111 & $4.75 \mathrm{E}-03$ & $2.24 \mathrm{E}-05$ & $1.33 \mathrm{E}-04$ \\
\hline $\operatorname{kam} 4$ & 328.4252 & 0.34812 & 0.35006 & $1.94 \mathrm{E}-03$ & $5.91 \mathrm{E}-06$ & $3.50 \mathrm{E}-05$ \\
\hline wr1 & 70.882184 & 0.17021 & 0.17223 & $6.90 \mathrm{E}-04$ & $9.73 E-06$ & \\
\hline wr2 & 70.882184 & 0.17664 & 0.17902 & $1.27 \mathrm{E}-03$ & $1.78 \mathrm{E}-05$ & \\
\hline wr3 & 70.882184 & 0.17475 & 0.17715 & $1.53 \mathrm{E}-03$ & $2.16 \mathrm{E}-05$ & \\
\hline wr4 4 & 70.882184 & 0.17688 & 0.17865 & $5.50 \mathrm{E}-04$ & $7.76 \mathrm{E}-06$ & \\
\hline
\end{tabular}

10 micrometer filter

\begin{tabular}{|c|c|c|c|c|c|c|}
\hline sample & $\begin{array}{l}\text { area sum } \\
\left(\mathrm{cm}^{2}\right)\end{array}$ & $\begin{array}{l}\text { dry pre-filter } \\
\text { mass (g) }\end{array}$ & $\begin{array}{l}\text { dry post-filter } \\
\text { mass (g) }\end{array}$ & $\begin{array}{c}\text { mass of } \\
\text { particles }(\mathrm{g})\end{array}$ & $\begin{array}{l}\text { PM density } \\
\left(\mathrm{g} / \mathrm{cm}^{\wedge} 2\right)\end{array}$ & $\begin{array}{c}\text { PM density - } \\
\text { corrected } \\
(\mathrm{g} / \mathrm{cm} 2)\end{array}$ \\
\hline $\operatorname{kam} 1$ & 384.06446 & 0.15487 & 0.16647 & $9.46 \mathrm{E}-03$ & $2.46 \mathrm{E}-05$ & $1.46 \mathrm{E}-04$ \\
\hline kam2 & 316.059 & 0.14893 & 0.15799 & $6.82 \mathrm{E}-03$ & $2.16 \mathrm{E}-05$ & $1.28 \mathrm{E}-04$ \\
\hline kam3 & 211.672 & 0.15062 & 0.15705 & $4.49 \mathrm{E}-03$ & $2.12 \mathrm{E}-05$ & $1.26 \mathrm{E}-04$ \\
\hline kam4 & 328.4252 & 0.16243 & 0.17503 & $1.06 \mathrm{E}-02$ & $3.24 \mathrm{E}-05$ & $1.92 \mathrm{E}-04$ \\
\hline $\mathrm{r} 1$ & 3802.0636 & 0.32389 & 0.34352 & $1.96 \mathrm{E}-02$ & $5.16 \mathrm{E}-06$ & $5.40 \mathrm{E}-05$ \\
\hline $\mathrm{r} 2$ & 1441.1767 & 0.16092 & 0.17267 & $9.61 \mathrm{E}-03$ & $6.67 \mathrm{E}-06$ & $6.97 \mathrm{E}-05$ \\
\hline r3 & 1499.3823 & 0.15547 & 0.16736 & $9.46 \mathrm{E}-03$ & $6.31 \mathrm{E}-06$ & $6.59 \mathrm{E}-05$ \\
\hline $\mathrm{r} 4$ & 952.03371 & 0.15025 & 0.16123 & $8.67 \mathrm{E}-03$ & $9.11 \mathrm{E}-06$ & $9.52 \mathrm{E}-05$ \\
\hline wr1 & 70.882184 & 0.1643 & 0.16844 & 0.00189 & $2.6664 \mathrm{E}-05$ & \\
\hline wr2 & 70.882184 & 0.15196 & 0.15616 & 0.00205 & $2.89212 \mathrm{E}-05$ & \\
\hline wr3 & 70.882184 & 0.15774 & 0.16247 & 0.00236 & $3.32947 \mathrm{E}-05$ & \\
\hline wr4 & 70.882184 & 0.14917 & 0.15459 & 0.00323 & $4.55686 \mathrm{E}-05$ & \\
\hline
\end{tabular}


The samples of Sedum kamchaticum had the greatest density of particles of all three surfaces. Additionally, correcting for the Leaf Area Index resulted in an increase in the density on the leaf surfaces - because initial area values neglect the fact that leaves are stacked upon one another (Table 1). Before the correction factor was implemented, the white roof sample shows the largest density of $10 \mu \mathrm{m}$ diameter particles, and a similar density of $0.2 \mu \mathrm{m}$ particles to that of S. kamchaticum (Figure 3). However, after the Leaf Area Index is accounted for, it appears that S. kamchaticum clearly collected the larger density of particles (Figure 4). It is worth noting that we did not obtain data for the fraction of $0.2 \mu \mathrm{m}$ particles for S. rupestre, so this is omitted from the bar chart.

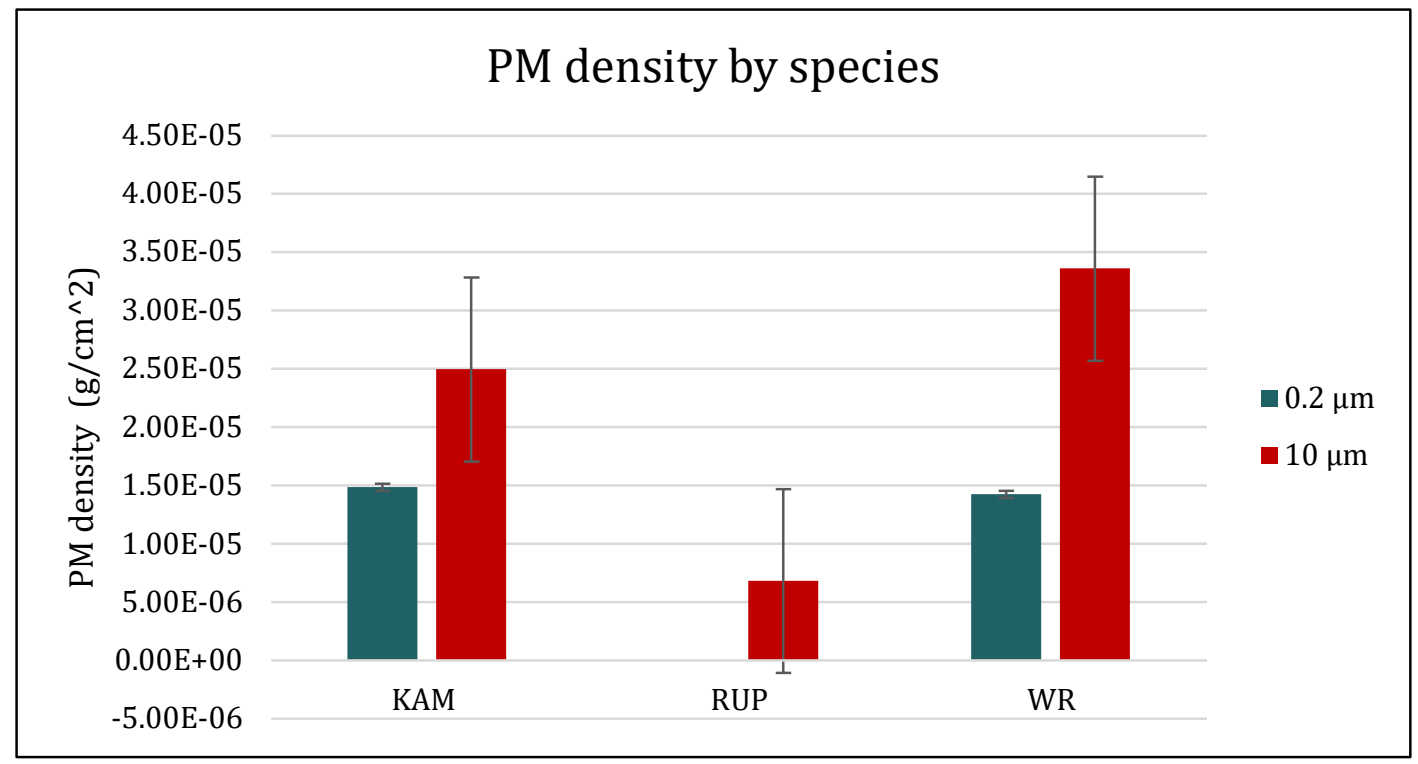

Figure 3. Particulate matter density found on the three different surfaces sampled in this experiment - notcorrected for Leaf Area Index 


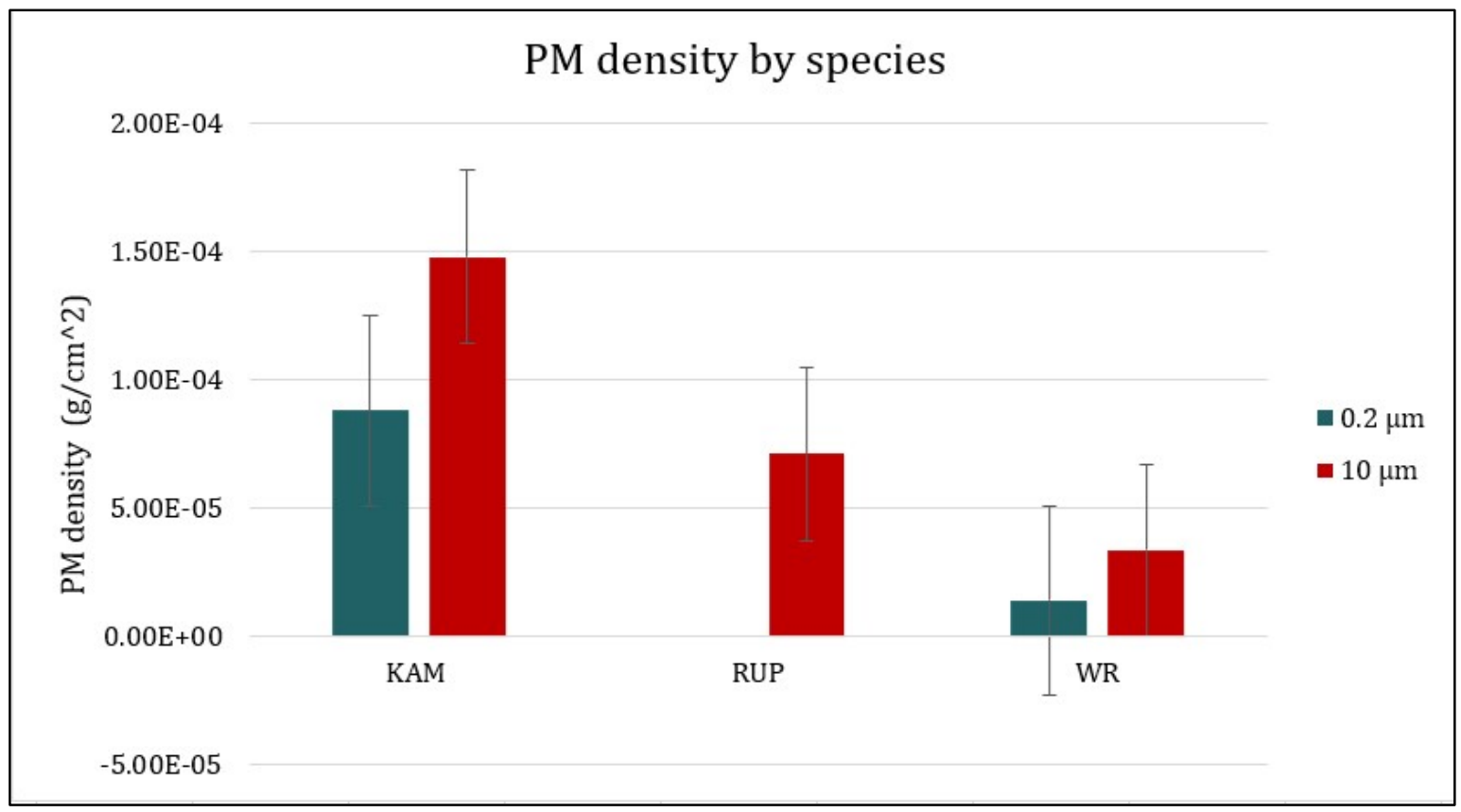

Figure 4. Particulate matter density found on the three different surfaces sampled in this experiment - corrected for Leaf Area Index

The data on the density of metals per species yielded similar results - S. kamchaticum had the largest density of metals of all three surfaces (Figure 5).

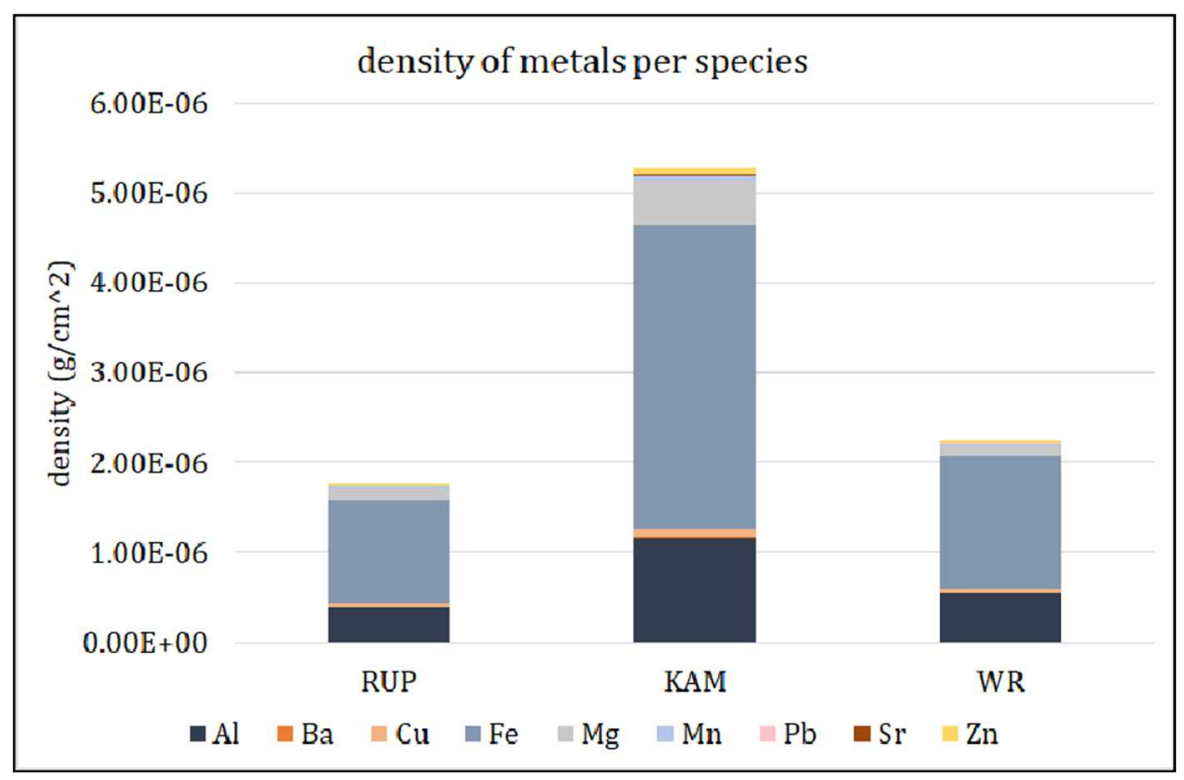

Figure 5. Density of metal species found on each surface

Additionally, the metals data showed that the most abundant metal found in the samples was Fe - in fact the proportions of metals present was similar for all three surfaces (Table 2). 
Table 2. Metals data for each surface showing mass of metal present in units of $\mathrm{mg} / \mathrm{sample}$. The percentage of each metal compared to the total particle mass is useful in comparing the tendency of different metals to attractto particular surfaces.

\begin{tabular}{rccccccccc} 
& $\mathrm{Al}$ & $\mathrm{Ba}$ & $\mathrm{Cu}$ & $\mathrm{Fe}$ & $\mathrm{Mg}$ & $\mathrm{Mn}$ & $\mathrm{Pb}$ & $\mathrm{Sr}$ & $\mathrm{Zn}$ \\
\cline { 2 - 9 } RUP & 0.2852 & 0.0066661 & 0.0266 & 0.8502 & 0.0984 & 0.0154 & 0.0019 & 0.002 & 0.0187 \\
\% of total mass & 0.60214 & 0.014072508 & 0.0561 & 1.79482 & 0.20768 & 0.03257 & 0.00409 & 0.00422 & 0.03946 \\
KAM & 0.1389 & 0.003255 & 0.0098 & 0.4024 & 0.0605 & 0.007 & 0.0008 & 0.0013 & 0.0091 \\
\% of total mass & 0.44214 & 0.010362822 & 0.03109 & 1.28101 & 0.1927 & 0.02244 & 0.00256 & 0.00416 & 0.02913 \\
WR & 0.1566 & 0.0027812 & 0.0122 & 0.4217 & 0.0339 & 0.0063 & 0.0018 & 0.0004 & 0.0092 \\
\% of total mass & 1.64287 & 0.029183307 & 0.12753 & 4.4248 & 0.35567 & 0.06641 & 0.01857 & 0.00415 & 0.09627
\end{tabular}

An Analysis of Variance (ANOVA) test and a post-hoc Tukey's Honestly Significant Difference (HSD) test were conducted with our particle density values (Table 1) in order to determine if the differences shown are statistically different. The result of this statistical analysis implied that the particle densities found on the white roof and those found on $S$. kamchaticum were significantly different, and the particle densities found on S. rupestre were also significantly different from those found on S. Kamchaticum (Appendix A).

\section{Discussion}

The results of the gravimetric method employed on the sample rinse water yielded information about the total mass of particles deposited onto each surface, which is a value of density (Table 1). In comparing these data to our method's model study - which looked at an urban forest in Poland - we can see particle density values with similar orders of magnitude; around $10^{-5} \mathrm{~g} / \mathrm{cm}^{2}$ (Dzierżanowski et al, 2011). The results of this study indicate that vegetative surfaces hold higher densities of particles (Figure 4). This aligns with the results of other studies - which have shown that vegetative surfaces yield lower downwind particulate matter concentrations, meaning a larger level of particles deposited onto the surface of the vegetation (Tong et al, 2016). A study looking at multiple green roofs in London produced values for S. album - a species whose small, cylindrical leaves can be 
compared to that of S. rupestre - in the range of $10^{-6}$. This is a lower density than the particles we measured on the vegetative surfaces and more in line with the white roof mass values (Speak et al, 2012). That being said, S. album had the lowest particle density of all the species they sampled; some of the other species sampled reached values as high as $0.8 \times 10^{-5}$ $\mathrm{g} / \mathrm{cm}^{2}$, which is much closer to the results we got for vegetative surfaces.

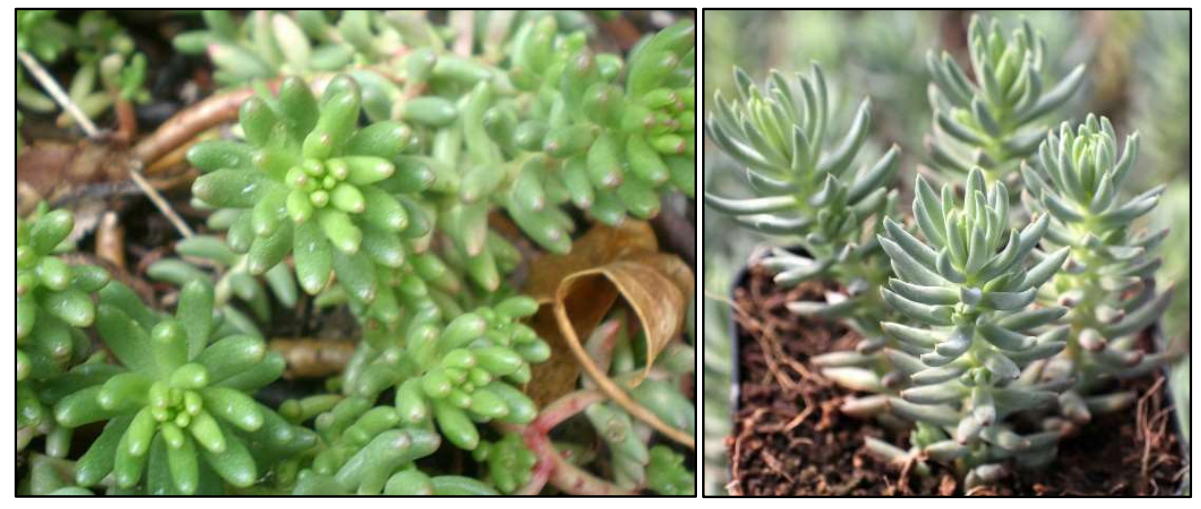

Figure 6. Sedum album (left) and Sedum rupestre (right) [credit: https://mountaincrestgardens.comand http://www.consultaplantas.com/]

With the assistance of Pennsylvania State University, we were able to determine the mass of several different metals present on the sampled surfaces (Table 2). Because they provided data in units of mass per sample, and we know the total mass of particles in the sample, we were able to determine the percentage of metals present. This is a valuable result because it allows us to differentiate between the metal retaining ability of each surface. In a majority of the instances, the proportions of metals present were quite similar for each sample - iron was the most abundant metal present for all surface types. However, it appears that the white roof sample actually had a much larger proportion of aluminum and iron than the vegetative surfaces (Table 2). It may be insightful to consider measuring the metals content of the particles found in the wax layer of the leaves to determine if the leaves may be absorbing the metals (Dzierżanowski et al, 2011) - which could account for the lower concentration of metals on the surface of the leaves. A study looking at the 
concentrations of metals found on tea leaves in Africa likewise found iron to be present in the highest proportion out of the metals analyzed (Mahlangeni et al, 2013). Noticeable differences among the samples within this study occurred in the proportions of manganese, lead and zinc present - all three of these metalsare a particular concern for human health. It has also been shown that concentration of particular metals depends heavily on potential emitters in the surrounding environment (Artwell, 2017 and Mahlangeni et al, 2013), which could explain why our findings differ from those in other similar studies. No arsenic was detected in the analysis of our samples, however in similar studies conducted near heavy industrial activity, arsenic has been measured at detectable values and has been linked directly to nearby emitters of metals (Bosco et al, 2004).

The high density of metals found on S. kamchaticum (Figure 5) can likely be attributed to the fact that this surface simply had a larger mass of deposited particles in general - however the larger proportion of particular metals on the white roof requires a novel explanation. Nevertheless, the results of this study propose potential differences between the metal deposition tendency of vegetation versus white roofs and this should be considered as an important avenue for future research. Despite the potential for white roofs to attract a greater level of harmful metals, it is worth noting that the installation of ecoroofs is motivated by the promise of a larger variety of benefits. Green roofs have also been shown to mitigate stormwater runoff and improve water quality, as well as cool water and the surrounding air (Berardi et al, 2013). Along with other sociocultural and environmental benefits of ecoroofs, there are many factors in deciding what type of roof (green or white) is most suitable for a particular project - this study simply looks at one of these many aspects.

Leaf Area Index (LAI) played an important role in dictating the density values of this 
study. Before Leaf Area Index was accounted for, the data portrays a larger density of $10 \mu \mathrm{m}$ diameter particles on the white roof compared to both plant species (Figure 3). One major reason for this confounding result is due to the fact that it is based on the assumption that each leaf received equal levels of particle deposition. Just because a particular leaf area is present does not necessarily mean that all of the area is being utilized for surface deposition - one major reason for this is because of leaf stacking. LAI is a way of accounting for the different growth patterns - and the affinity for leaf stacking - of varying species. After implementing each species' respective LAI (Figure 4) the data shows that the $S$. kamchaticum and S. rupestre samples had captured more particles.

\section{Conclusions}

- An analysis of particles collected on ecoroof vegetation and adjacent white roof surface has shown that vegetative surfaces collect a larger mass of particles per surface area (i.e., higher density)

- An inductively coupled plasma mass spectrometry revealed the mass of particular metals present in these samples - and has shown that although S. kamchaticum collected a greater density of particles, the white roof sample contained a larger proportion of specific metals, particularly $\mathrm{Al}$ and $\mathrm{Fe}$

- Additional research should be done to explore why we see differences between the affinity for the deposition of metals onto white roof versus vegetation. The resulting findings of additional work may greatly influence the decisions made by urban planners when it comes to the preference of ecoroofs over white roofs 


\section{References}

Artwell, K., France, N., \& Florence, K. (2017). Investigation of Some Metals in Leaves and Leaf Extracts of Lippia javanica: Its Daily Intake. Journal of Environmental and Public Health.

Baraldi, R., Neri, L., Costa, F., Facini, O., Rapparini, F., \& Carriero, G. (2019). Ecophysiological and micromorphological characterization of green roof vegetation for urban mitigation. Urban Forestry and Urban Greening, 37(January 2018), 24-32. https://doi.org/10.1016/j.ufug.2018.03.002

Beckett, K. P., Freer-Smith, P. H., \& Taylor, G. (1998). Urban woodlands: Their role in reducing the effects of particulate pollution. Environmental Pollution, 99(3), 347-360. https://doi.org/10.1016/S0269-7491(98)00016-5

Berardi, Umberto, et al. "State-of-the-Art Analysis of the Environmental Benefits of Green Roofs." Applied Energy, vol. 115, 2014, pp. 411-428., doi:10.1016/j.apenergy.2013.10.047.

Bosco, M. L., Varrica, D., \& Dongarrà, G. (2005). Case study: Inorganic pollutants associated with particulate matter from an area near a petrochemical plant. Environmental Research, 99(1), 18-30. https://doi.org/10.1016/j.envres.2004.09.011

Brantley, H. L., Hagler, G. S. W., J. Deshmukh, P., \& Baldauf, R. W. (2014). Field assessment of the effects of roadside vegetation on near-road black carbon and particulate matter. Science of the Total Environment, 468-469, 120-129. https://doi.org/10.1016/j.scitotenv.2013.08.001

Chen, L., Liu, C., Zou, R., Yang, M., \& Zhang, Z. (2016). Experimental examination of effectiveness of vegetation as a biofilter of particulate matters in the urban environment. Environmental Pollution, 208, 198-208. https://doi.org/10.1016/j.envpol.2015.09.006

Chen, L., Liu, C., Zhang, L., Zou, R., \& Zhang, Z. (2017). Variation in Tree Species Ability to Capture and Retain Airborne Fine Particulate Matter (PM2.5). Scientific Reports, 7(1), 1-11. https://doi.org/10.1038/s41598-017-03360-1

Dzierżanowski, Kajetan, et al. "Deposition of Particulate Matter of Different Size Fractions on Leaf Surfaces and in Waxes of Urban Forest Species." (2011), International Journal of Phytoremediation, pp. 1037-1046.

Janhäll, S. (2015). Review on urban vegetation and particle air pollution - Deposition and dispersion. Atmospheric Environment, 105, 130-137. https://doi.org/10.1016/j.atmosenv.2015.01.052

Joshi, S. V., \& Ghosh, S. (2014). On the air cleansing efficiency of an extended green wall: A CFD analysis of mechanistic details of transport processes. Journal of Theoretical Biology.

Li, Jian-Feng, et al. "Effect of Green Roof on Ambient CO2 Concentration." Building and Environment, vol. 45, no. 12, 2010, pp. 2644-2651., doi:10.1016/j.buildenv.2010.05.025.

Li, D., Bou-Zeid, E., \& Oppenheimer, M. (2014). The effectiveness of cool and green roofs as 
urban heat island mitigation strategies. Environmental Research Letters, 9(5), 055002. https://doi.org/10.1088/1748-9326/9/5/055002

Litschike, T., \& Kuttler, W. (2008). On the reduction of urban particle concentration by vegetation - A review. Meteorologische Zeitschrift, 17(3), 229-240. https://doi.org/10.1127/0941-2948/2008/0284

Liu, L., Guan, D., \& Peart, M. R. (2012). The morphological structure of leaves and the dust-retaining capability of afforested plants in urban Guangzhou, South China. Environmental Science and Pollution Research, 19(8), 3440-3449. https://doi.org/10.1007/s11356-012-0876-2

Mahlangeni, N. T., Moodley, R., \& Jonnalagadda, S. B. (2018). Elemental composition of Cyrtanthus obliquus and Lippia javanica used in South African herbal tonic, Imbiza. Arabian Journal of Chemistry, 11(1), 128-136. https://doi.org/10.1016/j.arabjc.2014.07.007

Moya, T. A., Dobbelsteen, A. V. D., Ottelé, M., \& Bluyssen, P. M. (2018). A review of green systems within the indoor environment. Indoor and Built Environment, 28(3), 298-309. doi: $10.1177 / 1420326 \times 18783042$

EPA. NAAQS Table. (2016, December 20). Retrieved from https://www.epa.gov/criteria-air-pollutants/naaqs-table

Ottelé, M., van Bohemen, H. D., \& Fraaij, A. L. A. (2010). Quantifying the deposition of particulate matter on climber vegetation on living walls. Ecological Engineering, 36(2), 154-162. https://doi.org/10.1016/j.ecoleng.2009.02.007

Pugh, T. A. M., MacKenzie, A. R., Whyatt, J. D., \& Hewitt, C. N. (2012). Effectiveness of green infrastructure for improvement of air quality in urban street canyons. Environmental Scienceand Technology, 46(14), 7692-7699. https://doi.org/10.1021/es300826w

Sæbø, A., Popek, R., Nawrot, B., Hanslin, H. M., Gawronska, H., \& Gawronski, S. W. (2012). Plant species differences in particulate matter accumulation on leaf surfaces. Science of the Total Environment, 427-428, 347-354. https://doi.org/10.1016/j.scitotenv.2012.03.084

Soriano, Joan B.; Abajobir, Amanuel Alemu et al. (2017). Global, regional, and national deaths, prevalence, disability-adjusted life years, and years lived with disability for chronic obstructive pulmonary disease and asthma, 1990-2015: a systematic analysis for The Global Burden of Disease Study 2015. The Lancet Respiratory Medicine.

Speak, A., Rothwell, J., Lindley, S., \& Smith, C. (2012). Urban particulate pollution reduction by four species of green roof vegetation in a UK city. Atmospheric Environment, 61, 283-293. doi: 10.1016/j.atmosenv.2012.07.043

Starry, Olyssa. (2013). The Comparative Effects of Three Sedum Species on Green Roof Stormwater Retention.

Stephens, B., Azimi, P., \& Leung, L. (2019). How Do Outdoor Pollutant Concentrations Vary Along the Height of a Tall Building? Council on Tall Buildings and Urban Habitat. 
Suravarapu, L. N., \& Baek, S.-O. (2016). Determination of heavy metals in the ambient atmosphere: A review. Toxicology and Industrial Health, 33(1), 79-96.

Tomašević, M., Vukmirović, Z., Rajšić, S., Tasić, M., \& Stevanović, B. (2005). Characterization of trace metal particles deposited on some deciduous tree leaves in an urban area. Chemosphere, 61(6),

753-760. https://doi.org/10.1016/j.chemosphere.2005.03.077

Tong, Z., Baldauf, R. W., Isakov, V., Deshmukh, P., \& Zhang, K. M. (2016). Roadside vegetation barrier designs to mitigate near-road air pollution impacts. Science of the Total Environment, 541, 920-927.

UN DESA - United Nations Department of Economic and Social Affairs. (2018). World Urbanization Prospects: The 2018 Revision.

Viecco, M., Vera, S., Jorquera, H., Bustamante, W., Gironás, J., Dobbs, C., \& Leiva, E. (2018). Potential of particle matter dry deposition on green roofs and living walls vegetation for mitigating urban atmospheric pollution in semiarid climates. Sustainability (Switzerland), 10(7). https://doi.org/10.3390/su10072431

Viippola, V., Yli-Pelkonen, V., Järvi, L., Kulmala, M., \& Setälä, H. (2020). Effects of forests on particle number concentrations in near-road environments across three geographic regions.

Environmental Pollution, 266(August). https://doi.org/10.1016/j.envpol.2020.115294

Wang, L., Huang, M., \& Li, D. (n.d.). Where Are White Roofs More Effective in Cooling the Surface? Geophysical Research Letters, 11.

Weerakkody, U., Dover, J. W., Mitchell, P., \& Reiling, K. (2018). Evaluating the impact of individual leaf traits on atmospheric particulate matter accumulation using natural and synthetic leaves. Urban Forestry and Urban Greening, 30(January), 98-107. https://doi.org/10.1016/j.ufug.2018.01.001

World Health Organization, W. (2005). WHO Air quality guidelines for particulate matter, ozone, nitrogen dioxide and sulfur dioxide: Global update 2005. 1-21. https://doi.org/10.1016/0004-6981(88)90109-6

Yang, J., Yu, Q., \& Gong, P. (2008). Quantifying air pollution removal by green roofs in Chicago. Atmospheric Environment, 42(31), 7266-7273 https://doi.org/10.1016/j.atmosenv.2008.07.0 03 


\section{Appendix A. ANOVA Results}

\section{white roof - S. kamchaticum}

\begin{tabular}{ccccc} 
& Count & Sum & Average & Variance \\
\cline { 2 - 5 } KAM & 4 & $9.98186 \mathrm{E}-05$ & $2.49547 \mathrm{E}-05$ & $2.69669 \mathrm{E}-11$ \\
$W R$ & 4 & 0.000134448 & $3.36121 \mathrm{E}-05$ & $7.1113 \mathrm{E}-11$
\end{tabular}

\begin{tabular}{r|cccccc} 
& $S S$ & $d f$ & $M S$ & $F$ & P-value & F crit \\
\hline $\begin{array}{r}\text { Between } \\
\text { Groups }\end{array}$ & $1.49903 \mathrm{E}-10$ & 1 & $1.49903 \mathrm{E}-10$ & 3.056758441 & 0.130987566 & 5.987377607 \\
Within Groups & $2.94239 \mathrm{E}-10$ & 6 & $4.90399 \mathrm{E}-11$ & & & \\
Total & $4.44143 \mathrm{E}-10$ & 7 & & & & \\
\hline
\end{tabular}

white roof - $S$. rupestre

\begin{tabular}{ccccc} 
& Count & Sum & Average & Variance \\
\cline { 2 - 5 }$W R$ & 4 & 0.000134448 & $3.36121 \mathrm{E}-05$ & $7.1113 \mathrm{E}-11$ \\
RUP & 4 & $2.72472 \mathrm{E}-05$ & $6.81181 \mathrm{E}-06$ & $2.75296 \mathrm{E}-12$
\end{tabular}

\begin{tabular}{r|cccccc} 
& SS & $d f$ & $M S$ & $F$ & P-value & F crit \\
\hline $\begin{array}{r}\text { Between } \\
\text { Groups }\end{array}$ & $1.43651 \mathrm{E}-09$ & 1 & $1.43651 \mathrm{E}-09$ & 38.89514564 & 0.000786634 & 5.987377607 \\
Within Groups & $2.21598 \mathrm{E}-10$ & 6 & $3.6933 \mathrm{E}-11$ & & & \\
Total & $1.65811 \mathrm{E}-09$ & 7 & & & & \\
\hline
\end{tabular}

S. rupestre - S. kamchaticum

\begin{tabular}{lcccc} 
& Count & Sum & Average & Variance \\
\cline { 2 - 5 } KAM & 4 & $9.98186 \mathrm{E}-05$ & $2.49547 \mathrm{E}-05$ & $2.69669 \mathrm{E}-11$ \\
RUP & 4 & $2.72472 \mathrm{E}-05$ & $6.81181 \mathrm{E}-06$ & $2.75296 \mathrm{E}-12$
\end{tabular}

\begin{tabular}{r|cccccc} 
& $S S$ & $d f$ & $M S$ & $F$ & P-value & F crit \\
\hline $\begin{array}{r}\text { Between } \\
\text { Groups }\end{array}$ & $6.58326 \mathrm{E}-10$ & 1 & $6.58326 \mathrm{E}-10$ & 44.30214475 & 0.000555901 & 5.987377607 \\
Within Groups & $8.91595 \mathrm{E}-11$ & 6 & $1.48599 \mathrm{E}-11$ & & & \\
Total & $7.47485 \mathrm{E}-10$ & 7 & & & & \\
\hline
\end{tabular}

